\title{
The prognostic significance of repeated prehospital shocks for out-of-hospital cardiac arrest survival
}

\author{
Alexis Cournoyer, $\mathrm{MD}^{* \dagger}$; Éric Notebaert, $\mathrm{MD}^{\dagger}, \mathrm{MSc}^{*}{ }^{\dagger}$; Sylvie Cossette, $\mathrm{PhD}^{\S \ddagger}$; Luc Londei-Leduc,

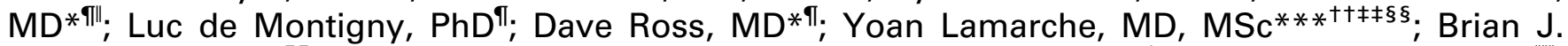

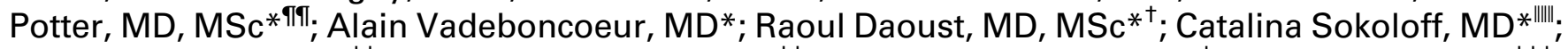

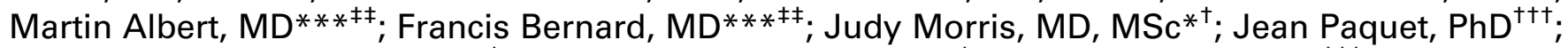 \\ Jean-Marc Chauny, MD, MSc ${ }^{*}$; Massimiliano Iseppon, $\mathrm{MD}^{*{ }^{\dagger}}$; Martin Marquis, $\mathrm{MSc}^{{ }^{\dagger+\dagger}}$; François de

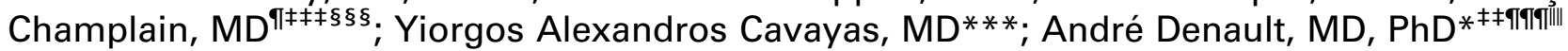

For a French translation of the original research, please see the Supplementary Material at DOI: $10.1017 / \mathrm{cem} .2018 .437$

\author{
CLINICIAN'S CAPSULE \\ What is known about the topic? \\ The prognostic implications of repeated shocks for out- \\ of-hospital cardiac arrest are uncertain. \\ What did this study ask? \\ What is the association between the number of pre- \\ hospital shocks and survival in patients suffering from an \\ out-of-hospital cardiac arrest? \\ What did this study find? \\ Survival remains possible even after a high number of \\ shocks for patients suffering from an OHCA. \\ Why does this study matter to clinicians? \\ The probabilities presented may prove useful in decision \\ modelling to guide resuscitation efforts for these \\ patients.
}

\section{ABSTRACT}

Objectives: Patients suffering from an out-of-hospital cardiac arrest (OHCA) associated with an initial shockable rhythm have a better prognosis than their counterparts. The implications of recurrent or refractory malignant arrhythmia in such context remain unclear. The objective of this study is to evaluate the association between the number of prehospital shocks delivered and survival to hospital discharge among patients in OHCA.

Methods: This cohort study included adult patients with an initial shockable rhythm over a 5-year period from a registry of OHCA in Montreal, Canada. The relationship between the number of prehospital shocks delivered and survival to discharge was described using dynamic probabilities. The association between the number of prehospital shocks delivered and survival to discharge was assessed using multivariable logistic regression.

Results: A total of 1,788 patients (78\% male with a mean age of 64 years) were included in this analysis, of whom $536(30 \%)$ received treatments from an advanced care paramedic. A third of the cohort (583 patients, 33\%) survived to hospital discharge. The probability of survival was highest with the first shock (33\% [95\% confidence interval 30\%-35\%]), but decreased to $8 \%$ (95\% confidence interval 4\%-13\%) following nine shocks. A higher number of prehospital shocks was independently associated with lower odds of survival (adjusted odds ratio $=0.88$ [95\% confidence interval 0.85-0.92], $p<0.001$ ).

Conclusion: Survival remains possible even after a high number of shocks for patients suffering from an OHCA with an initial shockable rhythm. However, requiring more shocks is independently associated with worse survival.

From the *Faculty of Medicine, Université de Montréal, Montréal, QC; †Department of Emergency Medicine, Hôpital du Sacré-Coeur de Montréal, Montréal, QC; $¥$ Research center, Institut de Cardiologie de Montréal, Montréal, QC; §Faculty of Nursing, Université de Montréal, Montréal, QC; ףCorporation d'Urgences-santé, Montréal, QC; IDepartment of Emergency Medicine, Centre Hospitalier de l'Université de Montréal, Montréal, QC; **Department of Medicine, Intensive Care, Hôpital du Sacré-Coeur de Montréal, Montréal, QC; ††Department of Surgery, Cardiac Surgery, Hôpital du Sacré-Coeur de Montréal, Montréal, QC; ¥‡Department of Medicine, Intensive Care, Institut de Cardiologie de Montréal, Montréal, QC; $\S \S$ Department of Surgery, Cardiac Surgery, Institut de Cardiologie de Montréal, Montréal, OC; ๆๆDepartment of Medicine, Cardiology, Centre Hospitalier de I'Université de Montréal, Montréal, OC; IIIDepartment of Medicine, Intensive Care, Centre Hospitalier de I'Université de Montréal, Montréal, QC; †††Research center, Hôpital du Sacré-Coeur de Montréal, Montréal, QC; ¥¥¥Faculty of Medicine, Université McGill, Montréal, QC; $\S \S \S$ Department of Emergency Medicine, Centre Universitaire de Santé McGill, Montréal, QC; and IT†ाDepartment of Anesthesiology, Institut de Cardiologie de Montréal, Montréal, OC

Correspondence to: Dr. Alexis Cournoyer, Hôpital du Sacré-Cœur, 5400 Gouin Ouest, Montréal, QC H4J 1C5; Email: alexiscournoyermus@gmail.com 


\section{RÉSUMÉ}

Objectifs: Les patients souffrant d'un arrêt cardiaque extrahospitalier (ACEH) dont le rythme initial est défibrillable sont à meilleur pronostic que si leur rythme initial ne l'est pas. Cependant, l'impact sur la survie de nécessiter de multiples défibrillations demeure incertain. L'objectif de cette étude est d'évaluer l'association entre le nombre de défibrillations préhospitalières et la survie au congé hospitalier chez les patients souffrant d'un ACEH.

Méthodes: Des patients adultes avec un rythme initial défibrillable tirés de cinq années d'un registre d'ACEH ont été inclus dans cette étude de cohorte. L'évolution de la survie au congé en fonction du nombre de défibrillations préhospitalières déjà administrées a été décrite à l'aide de probabilités dynamiques. L'association entre le nombre de défibrillations préhospitalières et la survie au congé a été évaluée à l'aide d'une régression logistique multivariée.

Résultats: Un total de 1,788 patients (Homme: 78\%; âge moyen: 64 ans) ont été inclus dans l'analyse. Parmi ceux-ci,
$536(30 \%)$ ont été traités par des paramédics prodiguant des soins avancés en réanimation. Un tiers de la cohorte (583 patients, 33\%) a survécu jusqu'à son congé hospitalier. La probabilité de survie était maximale à la première défibrillation (33\% [intervalle de confiance à $95 \% 30 \%-35 \%$ ]), puis diminuait jusqu'à $8 \%$ (intervalle de confiance à 95\% 4\%-13\%) suite à neuf défibrillations. Une association entre la mortalité et un nombre plus élevé de défibrillations a été observée (rapport des cotes ajustés $=0.88$ [intervalle de confiance à $95 \%$ 0.85-0.92], $p<0.001$ ).

Conclusions: II demeure possible de survivre à un $\mathrm{ACEH}$ même après un grand nombre de défibrillations. Cependant, nécessiter plus de défibrillations est associé à une moins bonne survie pour ces patients.

Keywords: defibrillation, out-of-hospital cardiac arrest, survival

\section{INTRODUCTION}

Across North America, over 365,000 people suffer a non-traumatic out-of-hospital cardiac arrest (OHCA) each year. ${ }^{1,2}$ Rates of survival for these patients remain low, with only $5 \%$ to $10 \%$ of all OHCA surviving to hospital discharge. ${ }^{1,3,4}$ However, patients with an initial shockable rhythm, such as ventricular fibrillation and pulseless ventricular tachycardia, have a better prognosis than patients whose initial rhythm is non-shockable (pulseless electrical activity or asystole). ${ }^{3,5-7}$ This may be explained by shockable rhythms being a marker of earlier intervention (i.e., prior to deterioration to asystole) or simply that the single best available therapy for patients suffering from a cardiac arrest (defibrillation) is only effective in patients with these rhythms. ${ }^{8-12}$

The efficacy of a single shock to terminate a malignant ventricular arrhythmia is reported to be over $85 \%$ when using a biphasic waveform. ${ }^{9}$ However, because of refractory (ventricular fibrillation not responding to the initial shocks) or recurrent (returning ventricular fibrillation after a period of non-shockable rhythm) arrhythmias, more than one shock is often required. ${ }^{13-16}$ While the patients requiring more shocks may be expected to have worse outcomes, the precise prognostic implications of having a recurrent or refractory malignant arrhythmia remain uncertain, and many medical decisions, such as the timing of patient transport or the decision to cease resuscitation efforts, could be aided by more reliable early survival prognostication. This is especially true in prehospital settings with low rates of prehospital advanced cardiac life support (ACLS) for which this has not been described so far. As such, a better understanding of the implications of the number of shocks delivered could help improve prehospital resuscitation practices. ${ }^{17,18}$

The main objective of this study was therefore to evaluate the association between the number of prehospital shocks delivered and the resuscitation outcomes (survival to discharge and prehospital return of spontaneous circulation [ROSC]) of patients suffering from an OHCA with an initial shockable rhythm, in a prehospital setting with low rates of prehospital ACLS. The secondary objective was to describe the number of shocks delivered in the specific population subgroup of patients having experienced prehospital ROSC.

\section{METHODS}

\section{Study design and settings}

This cohort study was derived from a registry of all OHCA occurring in the region of Montreal, Canada. It was carried out in association with the Hôpital du Sacré-Coeur de Montréal, the regional emergency medical services (EMS) agency (Urgences-santé) and the Université de Montréal and was approved by 
the Research Ethics Board of the Hôpital du SacréCoeur de Montréal with a waiver of written informed consent.

In Montreal, a single public tiered-response EMS agency coordinates all prehospital care for a population of over 2,000,000 people. First responders and paramedics treat patients suffering from OHCA using an automated external defibrillator when appropriate (ZOLL AED Pro ${ }^{\circledR}$ and ZOLL E series ${ }^{\circledR}$, respectively, using a sequence of $120 \mathrm{~J}-150 \mathrm{~J}-200 \mathrm{~J}$ ) and follow resuscitations protocols based on the American Heart Association guidelines. ${ }^{10,19}$ All paramedics can use an esophageal tracheal airway to assist ventilation during the resuscitation. ${ }^{19,20}$ In up to $25 \%$ of OHCA cases, advanced care paramedics are dispatched to provide prehospital ACLS, which includes the administration of epinephrine and amiodarone and the use of the ZOLL $\mathrm{E}$ series defibrillator in manual mode. ${ }^{12,20}$ In accordance with provincial law, advanced care paramedics do not perform endotracheal intubation. All of these defibrillators provide rectilinear biphasic waveform defibrillations.

\section{Methods and measurements}

The methods used to collect and extract the data for the initial registry have been described previously. ${ }^{3,18,21}$ Patient data are entered by the paramedic on a "run-sheet" following every call. Patients suffering from an OHCA are identified using these run-sheets. The pertinent information is then entered into a database that comprises demographic and clinical characteristics. Resuscitation outcome data were transferred from the discharge hospitals to the regional EMS agency or were readily available. The extracted data were subsequently validated.

\section{Selection of participants}

All patients age 18 years and older treated for an OHCA between April 2010 and December 2015 with an initial shockable rhythm, either ventricular fibrillation or pulseless ventricular tachycardia, were included in the present study. Patients with traumatic causes for arrest, do-not-resuscitate directives, or fitting "obviously dead" criteria (e.g., decapitation, advanced putrefaction) were excluded from both the registry and this analysis. ${ }^{19}$

\section{Outcome measures}

The primary outcome measure was survival to hospital discharge. The secondary outcome measure was any occurrence of prehospital ROSC of a duration of more than 30 seconds.

\section{Statistical analyses}

The entire available population with an initial shockable rhythm was used in this analysis. Continuous variables are presented as means with standard deviations or median and Q1-Q3, as appropriate, and categorical variables are presented as frequencies with percentages.

For the main objective, to ensure that this analysis would be immediately applicable for physicians providing resuscitation care, the relationship between the number of prehospital shocks delivered and the probability of both resuscitation outcomes was first analysed in a way to reflect the dynamic nature of clinical decision-making, such that each level of analysis represents the likelihood of the resuscitation outcome up to that number of shocks (dynamic or Bayesian probabilities). For example, because all patients received at least one shock, the results presented at " 1 shock" were derived from the entire cohort (and not from patients having received one shock only). Likewise, at "2 shocks," all patients having received two shocks or more were kept in the analysis. This analysis can be interpreted as one would a Kaplan-Meier curve. For the alternative analysis, patients were separated in two groups according to the number of prehospital shocks they received: less than three or at least three. This cut-off has been previously proposed to differentiate patients with better and worse prognoses. ${ }^{14}$ Moreover, the shock energy is lower with the first two shocks (120 J and $150 \mathrm{~J}$ ) compared with all subsequent ones $(200 \mathrm{~J})$.

Resuscitation outcomes (survival to hospital discharge and prehospital ROSC) of the patients included in these two groups were compared using Pearson's chisquare tests. In addition, a multivariable logistic regression model was planned using a standard approach (enter method) adjusting for pertinent variables (i.e., age, sex, initial call time, bystander cardiopulmonary resuscitation $[\mathrm{CPR}]$, witnessed arrest, time from call to arrival of EMS personnel, presence of first responders, presence of advanced care paramedics, intubation using an esophageal tracheal airway) to assess the independent association between the number of 
prehospital shocks administered (used as a continuous variable) and the resuscitation outcomes. ${ }^{22}$

For the secondary objective (describing the number of shocks necessary for patients having experienced ROSC over the course of their prehospital resuscitation), the appropriate measures of central tendency and dispersion of the number of prehospital shocks administered to that subgroup are presented as described previously. This analysis was necessarily limited to patients having experienced ROSC in the prehospital setting. That subgroup analysis was performed because, by definition, these patients had the potential to respond to treatment they received. The association between the number of prehospital shocks administered and survival to hospital discharge was also evaluated in this same subgroup of patients using the same methods described previously.

Statistical analyses were performed using SPSS Statistics 23 (IBM, Chicago, USA). All results are presented with their $95 \%$ confidence intervals (CI).

\section{RESULTS}

During the study period (April 1, 2010, to December 31,2015$)$, among 7,134 patients in the OHCA registry, 1,788 had an initial shockable rhythm and were included. Their demographic and clinical characteristics are presented in (Table 1). Less than a third of the included patients $(536,30 \%)$ received treatments from an advanced care paramedic. A total of 977 patients $(55 \%)$ were administered one or two prehospital shocks, whereas 774 (45\%) were administered three or more. Among all included patients, 583 (33\% [95\% CI 30\%-35\%]) survived to hospital discharge and 961 (54\% [95\% CI $51 \%-56 \%])$ experienced prehospital ROSC (Table 2). Included patients were administered a median number of two shocks (Q1-Q3: 1-5) (see Table 2).

The dynamic probabilities of survival and prehospital ROSC, according to the number of prehospital shocks having already been delivered, irrespective of whether the previous shocks were successful, are presented in (Figure 1. The probability of survival begins at $33 \%$ (95\% CI 30\%-35\%) for patients having received at least one shock and gradually lowers to $8 \%$ (95\% CI $4 \%-13 \%$ ) following nine shocks, without a pronounced inflection point. The same is observed for the probability of prehospital ROSC, which begins at 54\% (95\% CI 51\%-56\%) and

Table 1. Demographic and clinical characteristics of the included patients

\begin{tabular}{|c|c|c|c|}
\hline Variables & $\begin{array}{l}\text { Total cohort } \\
(\mathrm{n}=1,788)\end{array}$ & $\begin{array}{l}\text { Two defibrillations or less } \\
\qquad(\mathrm{n}=977)\end{array}$ & $\begin{array}{l}\text { Three shocks or more } \\
\qquad(\mathrm{n}=774)\end{array}$ \\
\hline Age, years (mean, SD) & $64(16)$ & $64(16)$ & $64(15)$ \\
\hline Sex, male (N, \%) & $1,396(78)$ & $734(74)$ & $662(84)$ \\
\hline Initial call between 0800 and $1600 \mathrm{hr}(\mathrm{N}, \%)$ & $807(45)$ & $448(45)$ & $359(45)$ \\
\hline Initial call between 1600 and $2400 \mathrm{hr}$ & $631(35)$ & $358(36)$ & $273(35)$ \\
\hline Initial call between 2400 and $0800 \mathrm{hr}$ & $349(20)$ & $190(19)$ & $159(20)$ \\
\hline Unwitnessed arrest (N, \%) & $375(21)$ & $213(21)$ & $162(21)$ \\
\hline Bystander witnessed & $1,170(65)$ & $592(59)$ & $578(73)$ \\
\hline First responder or paramedic witnessed & $243(14)$ & $191(19)$ & $52(7)$ \\
\hline No bystander CPR (N, \%) & $908(51)$ & $465(47)$ & $443(56)$ \\
\hline Bystander CPR & $629(35)$ & $336(34)$ & $293(37)$ \\
\hline First responder or paramedic witnessed & $243(14)$ & $191(19)$ & $52(7)$ \\
\hline Delay from call to arrival of EMS personnel, minutes (median, Q1-Q3) & $6.1(5.1-7.8)$ & $5.1(6.1-8.0)$ & $6.1(5.1-7.6)$ \\
\hline Presence of first responders (N, \%) & $1,040(58)$ & $537(54)$ & $503(64)$ \\
\hline Presence of advanced care paramedics $(\mathrm{N}, \%)$ & $536(30)$ & $255(26)$ & $281(36)$ \\
\hline Intubation using an esophageal tracheal airway (N, \%) & $1,177(66)$ & $531(53)$ & $646(82)$ \\
\hline At least one dose of epinephrine given $(N, \%)$ & $295(17)$ & $115(13)$ & $180(23)$ \\
\hline If given, number of epinephrine dose (median, Q1-Q3) & $2(2-5)$ & $2(2-5)$ & $2(2-5)$ \\
\hline \multicolumn{4}{|l|}{ No dose of amiodarone given (N, \%) } \\
\hline No amiodarone given & $1,688(94)$ & 982 (99) & $706(89)$ \\
\hline One dose of amiodarone given (300 mg) & $63(4)$ & $11(1)$ & $52(7)$ \\
\hline Two doses of amiodarone given (450 mg) & $37(2)$ & $2(0)$ & $34(4)$ \\
\hline
\end{tabular}


Table 2. Resuscitation outcomes of patients with an initial shockable rhythm

\begin{tabular}{|c|c|c|c|c|}
\hline Variables & $\begin{array}{l}\text { Total cohort } \\
(\mathrm{n}=1,788)\end{array}$ & $\begin{array}{l}\text { Two prehospital shocks } \\
\text { or less } \\
(\mathrm{n}=977)\end{array}$ & $\begin{array}{l}\text { Three prehospital shocks } \\
\text { or more } \\
\text { (n }=774)\end{array}$ & Odds ratio \\
\hline Survival to hospital discharge $(\mathrm{N}, \%)$ & $583(33)$ & $408(41)$ & $175(22)$ & $0.41(0.33-0.50)$ \\
\hline Prehospital ROSC (N, \%) & $961(54)$ & $641(64)$ & $320(40)$ & $0.38(0.31-0.46)$ \\
\hline $\begin{array}{l}\text { Number of prehospital shocks administered } \\
\text { (median, Q1-O3) }\end{array}$ & $2(1-5)$ & $1(0-2)$ & $5(4-8)$ & - \\
\hline
\end{tabular}

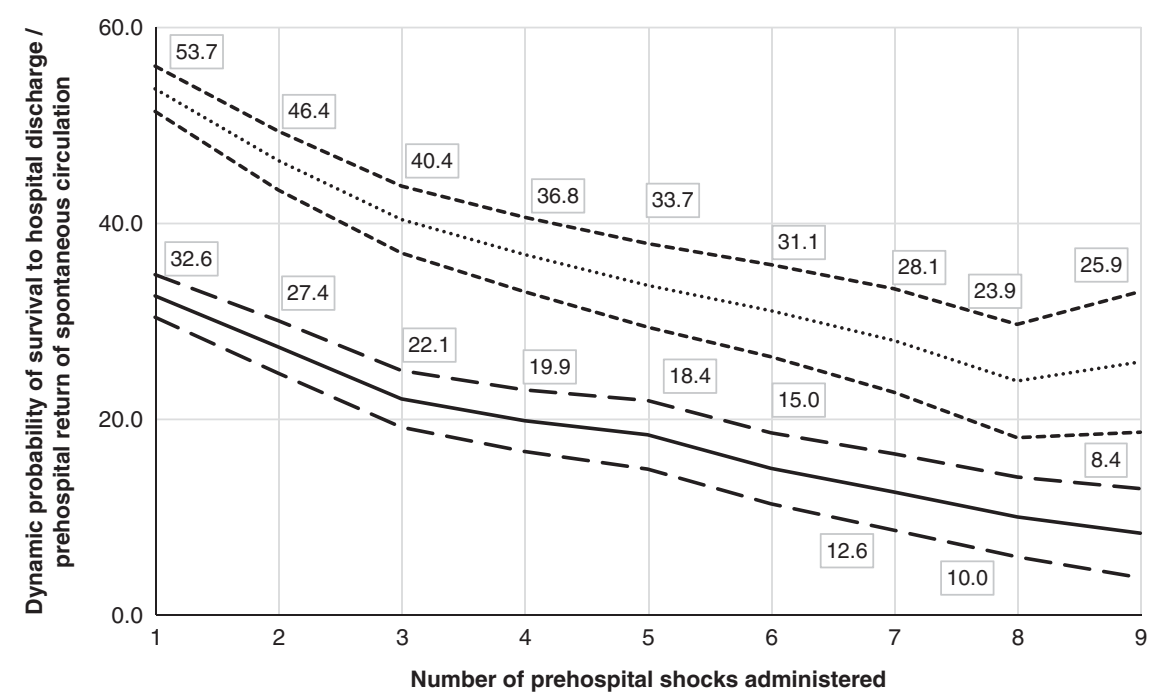

Figure 1. Dynamic probabilities of survival to hospital discharge (full line) and prehospital return of spontaneous circulation (dotted line) with their respective confidence intervals (large dash and small dash) according to the number of prehospital shocks already administered.

lowers to $24 \%$ (95\% CI $18 \%-30 \%)$ following nine shocks.

Patients having received three shocks or more were less likely to survive to hospital discharge ( $22 \% \mathrm{v} .41 \%$, odds ratio $[\mathrm{OR}]=0.41[95 \%$ CI $0.33-0.50], p<0.001$ ) than their counterparts (see Table 2). They were also less likely to experience prehospital ROSC $(40 \% \mathrm{v}$. $64 \%, \mathrm{OR}=0.38$ [95\% CI 0.31-0.46], $p<0.001$ ) (see Table 2). In multivariable logistic regression models, the number of prehospital shocks received was independently associated with lower odds of survival (adjusted OR [AOR] $=0.88 \quad[95 \%$ CI $0.85-0.92]$, $p<0.001$; Hosmer-Lemeshow goodness of fit test: $p=0.28$; c-statistic $=0.81)$ and with lower odds of prehospital ROSC $(\mathrm{AOR}=0.85 \quad$ [95\% CI 0.82-0.88], $p<0.001$; Hosmer-Lemeshow goodness of fit test: $p=0.35 ; \quad$ c-statistic $=0.80) \quad($ Table 3 and Appendix 1 [online]).
Among the 961 patients who experienced prehospital ROSC, 556 (58\% [95\% CI 55\%-61\%]) survived to hospital discharge and $320(33 \%)$ received three prehospital shocks or more (see Table 3). The median number of prehospital shocks they received was 2 [Q1Q3: 1-3] (see Table 3). Among patients who experienced prehospital ROSC, patients having received three prehospital shocks or more were also less likely to survive to hospital discharge $(50 \%$ v. $62 \%, \mathrm{OR}=0.62[95 \% \mathrm{CI}$ 0.47-0.81], $p<0.001$ ) than their counterparts (Appendix 2 [online]). In a multivariable logistic regression model, the number of prehospital shocks administered was independently associated with poorer survival to hospital discharge (AOR 0.95 [95\% CI 0.89-1.00], $p=0.045$ ).

\section{DISCUSSION}

In this large cohort of OHCA presenting with a shockable initial rhythm, the number of shocks was 


\begin{tabular}{|c|c|c|}
\hline Variables & AOR $(95 \% \mathrm{Cl})$ & $p$-value \\
\hline Number of shocks (1 more shock) & $0.88(0.85-0.92)$ & $<0.001$ \\
\hline Age (1 year older) & $0.97(0.96-0.97)$ & $<0.001$ \\
\hline Gender, male sex & $0.98(0.73-1.30)$ & 0.87 \\
\hline Initial call between 0800 and $1600 \mathrm{hr}$ & * & - \\
\hline Initial call between 1600 and $2400 \mathrm{hr}$ & $1.01(0.77-1.32)$ & 0.95 \\
\hline Initial call between 2400 and $0800 \mathrm{hr}$ & $1.08(0.78-1.50)$ & 0.64 \\
\hline Unwitnessed arrest & * & - \\
\hline Bystander witnessed & $2.53(1.80-3.57)$ & $<0.001$ \\
\hline First responder or paramedic witnessed & $3.73(2.37-5.85)$ & $<0.001$ \\
\hline No bystander CPR & * & - \\
\hline Bystander CPR & $1.26(0.97-1.63)$ & 0.086 \\
\hline First responder or paramedic witnessed & $\dagger$ & $\dagger$ \\
\hline Presence of first responders & $0.97(0.75-1.25)$ & 0.80 \\
\hline Presence of advanced care paramedics & $1.20(0.92-1.56)$ & 0.19 \\
\hline Intubation using an esophageal tracheal airway & $0.20(0.15-0.25)$ & $<0.001$ \\
\hline Delay from call to arrival of EMS personnel ( 1 more minute before their arrival) & $0.97(0.94-1.00)$ & 0.055 \\
\hline
\end{tabular}

independently associated with lower rates of prehospital ROSC and survival to hospital discharge. Moreover, although outcomes were significantly worse with more shocks, no clear inflection point in the dynamic probabilities could be identified. These probabilities presented may well prove useful in decision modelling to guide resuscitation efforts, especially for settings with low rates of prehospital ACLS for which this had not been described so far.

In the present study, it was observed that the probability of survival to discharge in patients with an initial shockable rhythm diminishes gradually with the number of defibrillation attempts from $33 \%$ at the first to $8 \%$ at the ninth. Similarly, the probability of prehospital ROSC diminishes gradually from $54 \%$ to $26 \%$ after nine defibrillations. Interestingly, these results are similar to the ones observed by Holmen et al. for the survival outcome (1-3 shocks $=42.9 \%$ and $>10$ shocks $=7.5 \%$ ), despite differences in prehospital care between the studies. ${ }^{14}$ Indeed, most patients received ACLS interventions in Holmen's study (73\% received epinephrine), whereas the majority did not in the present study (17\% received epinephrine). This observation would seem to corroborate the finding that prehospital ACLS does not appear to increase the medium-term outcomes of patients suffering from OHCA, even for patients with a shockable rhythm. ${ }^{3,14,23,24}$ On the other hand, Jouffroy et al. observed higher probabilities of prehospital ROSC than in the present study, perhaps explained by on-site prehospital ACLS provided by a specialized physician in that study. ${ }^{13}$ Although not clearly associated with improved survival to hospital discharge, ACLS interventions (e.g., vasopressors and antiarrhythmics) have been shown to increase the rate of ROSC. ${ }^{3,23,25}$ On the other hand, Hasegawa et al. observed a slightly higher survival in their cohort compared to the present one, but only included patients with a witnessed collapse who are known to have a better prognosis. ${ }^{5,16}$ While these studies presented outcomes for patients having received a selected number of shocks, the present study is the only one to present probabilities that are easily usable by providers during the resuscitation.

In the current study, no clear inflection point could be observed in the dynamic probabilities of survival. On the contrary, in the studies of Hasegawa and Jouffroy, cut-offs of three and four shocks were proposed to predict survival and prehospital ROSC. ${ }^{13,16}$ The absence of an obvious inflection point indicates that the arbitrary use of a specific cut-off is probably not sufficiently sensitive or specific to allow them to be used independently of other factors in clinical decisionmaking. 
The present results further our understanding of the prognostic implications of multiple shocks. One possible interpretation of this analysis is that all patients with an initial shockable rhythm, even those where a large number of shocks was administered, have a chance of survival well over the often suggested threshold of medical futility in resuscitation. ${ }^{17}$ Indeed, survival nearing $10 \%$ is likely sufficient to conclude that such patients not be considered for prehospital terminationof-resuscitation. ${ }^{14,17,26}$

The observation that more shocks are associated with worse resuscitation outcomes is likely explained by two factors. Firstly, requiring more shocks implies a longer period of CPR, which is strongly associated with the resuscitation outcomes. ${ }^{27}$ In addition, the patients responding more rapidly to a shock might have a less severe underlying disease (e.g., infarct size, genetic predisposition) or a shorter delay before its treatment. ${ }^{28-30}$ Nevertheless, it bears noting that a third of the patients who experienced ROSC required three shocks or more.

Another important interpretation of this analysis is that it might be critical to ensure the efficiency of first shocks. The best way to improve first-shock success is most likely to reduce the delay between circulatory collapse and the initial defibrillation attempt, which likely implies both optimizing the prehospital organization of care services and increasing public access to automated external defibrillators. ${ }^{31-33}$ Increasing the energy of initial shocks has also been proposed as a way to improve their efficiency, but evidence is lacking so far to support such a practice. $9,34,35$ Whether adding a short acting beta-blocker to the pharmaceutical cocktail that these patients receive early in resuscitation efforts or attempting a double sequential defibrillation remains a promising avenue for future research. ${ }^{36-38}$

\section{LIMITATIONS}

By design, all patient data were derived from information available in the EMS patient record. As such, it was not possible to know whether multiple shocks were administered because of a refractory versus a recurrent arrhythmia. It is possible that patients suffering from a recurrent arrhythmia would have a better prognosis than patients suffering from a refractory arrhythmia and, consequently, that these two populations' dynamic probabilities of survival differ. It was also not possible to know whether some patients had received defibrillation attempts from a public-access defibrillator prior to the arrival of emergency responders. Having these data available could have flattened the dynamic probabilities curve even more and increased the difference observed between groups. Neurologic outcomes were unavailable in this study. It would have been interesting to evaluate these outcomes because patients with a high number of shocks might be at a higher risk of brain ischemia and of poor neurologic outcomes than the majority of patients surviving from an OHCA. Given the nature of the prehospital system in the Montreal region, only a minority of patients received antiarrhythmic medications. Although these have never been shown to increase the long-term survival of patients with OHCA, they do increase the rate of ROSC and could also influence the rate of recurring or refractory arrhythmias (and consequently shocks), which could make the present results less generalizable in settings with high rates of prehospital ACLS. ${ }^{24}$ Additionally, although this study included a large and comprehensive multicentre data set of OHCA, caution would be recommended in extrapolating these results to regions with differences in the geographic parameters, availability of advanced care services, treatment standards, or patient demographics.

\section{CONCLUSIONS}

Survival remains possible even after a high number of shocks for patients suffering from an OHCA with an initial shockable rhythm. In a prehospital setting with low rates of prehospital ACLS, the probability of survival to hospital discharge for these patients diminishes gradually with the number of defibrillation attempts from $33 \%$ to $8 \%$ after nine shocks have been administered. There does not seem to be an evident inflection point in the probabilities of survival that would predict bad resuscitation outcomes, and the number of shocks received should not influence treatment decisions alone. Requiring more shocks is independently associated with worst outcomes in that population. Future studies should describe the dynamic probabilities of good neurologic outcomes of two specific subgroups of patients requiring multiple shocks, patients with a refractory arrhythmia, and patients with a recurrent arrhythmia.

Financial support: This project received funding from the "Département de médecine familiale et de médecine d'urgence de l'Université de Montréal" and the "Fonds des urgentistes de l'Hôpital du Sacré-Coeur de Montréal." 
Competing interests: Dr. André Denault is part of a speakers bureau for Medtronic, Edwards, Masimo, and CAE Healthcare. All other authors have no conflict of interest to declare.

\section{SUPPLEMENTARY MATERIAL}

To view supplementary material for this article, please visit https://doi.org/10.1017/cem.2018.437

\section{REFERENCES}

1. Mozaffarian D, Benjamin EJ, Go AS, et al. Heart disease and stroke statistic s - 2015 update: a report from the American Heart Association. Circulation 2015;131(4): e29-322.

2. Gardner MJ, Leather R, Teo K. Prevention of sudden death from ventricular arrhythmia. Epidemiology. Can 7 Cardiol 2000;16(Suppl C):10C-2C.

3. Cournoyer A, Notebaert É, Iseppon M, et al. Prehospital advanced cardiac life support for out-of-hospital cardiac arrest: a cohort study. Acad Emerg Med 2017;24 (9):1100-9.

4. Weisfeldt ML, Sitlani CM, Ornato JP, et al. Survival after application of automatic external defibrillators before arrival of the emergency medical system: evaluation in the resuscitation outcomes consortium population of 21 million. 7 Am Coll Cardiol 2010;55(16):1713-20.

5. Rea TD, Cook AJ, Stiell IG, et al. Predicting survival after out-of-hospital cardiac arrest: role of the Utstein data elements. Ann Emerg Med 2010;55(3):249-57.

6. Sasson C, Rogers MA, Dahl J, Kellermann AL. Predictors of survival from out-of-hospital cardiac arrest: a systematic review and meta-analysis. Circ Cardiovasc Qual Outcomes 2010;3(1):63-81.

7. Meaney PA, Nadkarni VM, Kern KB, et al. Rhythms and outcomes of adult in-hospital cardiac arrest. Crit Care Med 2010;38(1):101-8.

8. Waalewijn RA, Nijpels MA, Tijssen JG, Koster RW. Prevention of deterioration of ventricular fibrillation by basic life support during out-of-hospital cardiac arrest. Resuscitation 2002;54(1):31-6.

9. Morrison LJ, Henry RM, Ku V, et al. Single-shock defibrillation success in adult cardiac arrest: a systematic review. Resuscitation 2013;84(11):1480-6.

10. Kleinman ME, Brennan EE, Goldberger ZD, et al. Part 5: adult basic life support and cardiopulmonary resuscitation quality: 2015 American Heart Association guidelines update for cardiopulmonary resuscitation and emergency cardiovascular care. Circulation 2015;132(18 Suppl 2):S414-35.

11. Brooks SC, Anderson ML, Bruder E, et al. Part 6: alternative techniques and ancillary devices for cardiopulmonary resuscitation: 2015 American Heart Association guidelines update for cardiopulmonary resuscitation and emergency cardiovascular care. Circulation 2015;132(18 Suppl 2): S436-43.

12. Link MS, Berkow LC, Kudenchuk PJ, et al. Part 7: adult advanced cardiovascular life support: 2015 American Heart Association guidelines update for cardiopulmonary resuscitation and emergency cardiovascular care. Circulation 2015;132(18 Suppl 2):S444-64.

13. Jouffroy R, Ravasse P, Saade A, et al. Number of prehospital defibrillation shocks and the return of spontaneous circulation in out-of-hospital cardiac arrest. Turk $\mathcal{F}$ Anaesthesiol Reanim 2017;45(6):340-5.

14. Holmen J, Hollenberg J, Claesson A, et al. Survival in ventricular fibrillation with emphasis on the number of defibrillations in relation to other factors at resuscitation. Resuscitation 2017;113:33-8.

15. Sakai T, Iwami T, Tasaki $\mathrm{O}$, et al. Incidence and outcomes of out-of-hospital cardiac arrest with shock-resistant ventricular fibrillation: data from a large populationbased cohort. Resuscitation 2010;81(8):956-61.

16. Hasegawa $M$, Abe $T$, Nagata $T$, et al. The number of prehospital defibrillation shocks and 1-month survival in patients with out-of-hospital cardiac arrest. Scand 7 Trauma Resusc Emerg Med 2015;23:34.

17. Morrison LJ, Visentin LM, Kiss A, et al. Validation of a rule for termination of resuscitation in out-of-hospital cardiac arrest. N Engl 7 Med 2006;355(5):478-87.

18. Cournoyer A, Notebaert É, de Montigny L, et al. Potential impact of a prehospital redirection system for refractory cardiac arrest. Resuscitation 2017;119:37-42.

19. Ministère de la Santé et des Services Sociaux du Québec. Protocoles d'intervention clinique à l'usage des techniciens ambulanciers-paramédics. 6th ed. 2016. Available at: https:// www.urgences-sante.qc.ca/wp-content/uploads/2016/05/ 0-PICTAP-2015_Version-Officielle_MD_2016-05-17.pdf.

20. Département de médecine préhospitalière de l'Hôpital du Sacré-Cœur de Montréal. Protocoles d'intervention clinique à l'usage des techniciens ambulanciers-paramédics en soins avancés. 5th ed. 2013. Available at: https://www.urgencessante.qc.ca/wp-content/uploads/2014/03/PICTAP-2013_ 2014_02_07.pdf.

21. Cournoyer A, Notebaert E, de Montigny L, et al. Impact of the direct transfer to percutaneous coronary interventioncapable hospitals on survival to hospital discharge for patients with out-of-hospital cardiac arrest. Resuscitation 2018;125:28-33.

22. Perkins GD, Jacobs IG, Nadkarni VM, et al. Cardiac arrest and cardiopulmonary resuscitation outcome reports: update of the Utstein resuscitation registry templates for out-ofhospital cardiac arrest: A statement for healthcare professionals from a task force of the International Liaison Committee on Resuscitation (American Heart Association, European Resuscitation Council, Australian and New Zealand Council on Resuscitation, Heart and Stroke Foundation of Canada, InterAmerican Heart Foundation, Resuscitation Council of Southern Africa, Resuscitation Council of Asia) and the American Heart Association Emergency Cardiovascular Care Committee and the Council on Cardiopulmonary, Critical Care, Perioperative and Resuscitation. Resuscitation 2015;96:328-40.

23. Stiell IG, Wells GA, Field B, et al. Advanced cardiac life support in out-of-hospital cardiac arrest. $N$ Engl $7 \mathrm{Med}$ 2004;351(7):647-56.

24. Kudenchuk PJ, Brown SP, Daya M, et al. Amiodarone, lidocaine, or placebo in out-of-hospital cardiac arrest. $N$ Engl 7 Med 2016;374(18):1711-22. 
25. Olasveengen TM, Sunde K, Brunborg C, et al. Intravenous drug administration during out-of-hospital cardiac arrest: a randomized trial. 7AMA 2009;302(20):2222-9.

26. Group S-KS. A new rule for terminating resuscitation of out-of-hospital cardiac arrest patients in Japan: a prospective study. 7 Emerg Med 2017;53(3):345-52.

27. Goto Y, Funada A, Goto Y. Relationship between the duration of cardiopulmonary resuscitation and favorable neurological outcomes after out-of-hospital cardiac arrest: a prospective, nationwide, population-based cohort study. 7 Am Heart Assoc 2016;5(3):e002819.

28. De Maio VJ, Stiell IG, Wells GA, Spaite DW; Ontario Prehospital Advanced Life Support Study G. Optimal defibrillation response intervals for maximum out-of-hospital cardiac arrest survival rates. Ann Emerg Med 2003;42(2):242-50.

29. Gheeraert PJ, De Buyzere ML, Taeymans YM, et al. Risk factors for primary ventricular fibrillation during acute myocardial infarction: a systematic review and meta-analysis. Eur Heart 7 2006;27(21):2499-510.

30. Aouizerat BE, Vittinghoff E, Musone SL, et al. GWAS for discovery and replication of genetic loci associated with sudden cardiac arrest in patients with coronary artery disease. BMC Cardiovasc Disord 2011;11:29.

31. Stiell IG, Wells GA, Field BJ, et al. Improved out-ofhospital cardiac arrest survival through the inexpensive optimization of an existing defibrillation program: OPALS study phase II. Ontario prehospital advanced life support. FAMA 1999;281(13):1175-81.
32. Ringh $M$, Jonsson $M$, Nordberg $P$, et al. Survival after public access defibrillation in Stockholm, Sweden - a striking success. Resuscitation 2015;91:1-7.

33. Briard JN, de Montigny L, Ross D, et al. Is distance to the nearest registered public automated defibrillator associated with the probability of bystander shock for victims of out-of-hospital cardiac arrest? Prehosp Disaster Med 2018;33 (2):153-9.

34. Anantharaman V, Tay SY, Manning PG, et al. A multicentre prospective randomized study comparing the efficacy of escalating higher biphasic versus low biphasic energy defibrillations in patients presenting with cardiac arrest in the inhospital environment. Open Access Emerg Med 2017;9:9-17.

35. Emmerson AC, Whitbread M, Fothergill RT. Double sequential defibrillation therapy for out-of-hospital cardiac arrests: the London experience. Resuscitation 2017;117:97-101.

36. Driver BE, Debaty G, Plummer DW, Smith SW. Use of esmolol after failure of standard cardiopulmonary resuscitation to treat patients with refractory ventricular fibrillation. Resuscitation 2014;85(10):1337-41.

37. Lee YH, Lee KJ, Min YH, et al. Refractory ventricular fibrillation treated with esmolol. Resuscitation 2016;107: 150-5.

38. Hajjar K, Berbari I, El Tawil C, et al. Dual defibrillation in patients with refractory ventricular fibrillation: review and case report. Am J Emerg Med 2018;36 (8):1474-9. 